\title{
Vibration Discomfort Levels Caused by Blasting According to Gender
}

\author{
Tugce Ongen*, Gurcan Konak, Dogan Karakus \\ Department of Mining Engineering, Engineering Faculty, Dokuz Eylul University, Izmir 35390, Turkey
}

Corresponding Author Email: tugce.ongen@deu.edu.tr

https://doi.org/10.18280/eesrj.070303

Received: 10 June 2020

Accepted: 29 August 2020

\section{Keywords:}

blast-induced vibration, vibration measurements, survey studies, discomfort levels

\begin{abstract}
Several mines and excavation work with blasting are within city borders or close to settled areas due to expanding the population. People living in these areas can be made uncomfortable by the blast vibrations, even if particle velocities are within the permissible levels for structures according to regulations. Hence, there is a need for research on the perception of blast-induced vibration levels on human. As is known, there are biological differences between men and women. Also, they differ in many psychological and behavioral aspects. Thus, the response of women and men to vibration will be different. Considering this situation, we investigated how gender affects the level of being uncomfortable with blast-induced ground vibration. In this study, volunteer participants taken to the limestone quarry were surveyed about vibrations exposure, while blast vibrations were measured as a particle velocity. Peak particle velocities measured between $0.80 \mathrm{~mm} / \mathrm{s}$ and $17.40 \mathrm{~mm} / \mathrm{s}$. Scaled distances were calculated and PPV-scaled distances graphs were plotted. Vibration discomfort levels were determined and added on these graphs according to gender. According to the results, it is clear that the perception limit is the same for women and men but the annoyance levels change according to gender especially for high PPV values.
\end{abstract}

\section{INTRODUCTION}

In mining operations and rock excavation works vibrations occur due to blasting. In other words, while most of the energy generated during blasting operations is used to break the rock, wasted energy also creates vibration. Several mines especially quarries in Turkey are close to cities and towns. Excavation works with blasting are used commonly for fundation constructions located in urban areas, as well. Blasting operations in these areas causes several complaints. To prevent these complaints, it is common to determine the peak particle velocities and their potential effects of blast-induced vibration on structures. For this purpose, regulations in Turkey related to blast vibrations, which is named Regulation of Environmental Noise Management, 2010 [1], were developed. But it includes only vibration damage criteria of aboveground structures. Although there are various regulations for perception of mechanical vibrations [2], there is not any assessment about human perception level of vibration in Regulation of Environmental Noise Management. The perception and annoyance limit for mechanical vibrations cannot be used for blasting. Because the frequency, duration, and amplitude of the mechanical vibration differ from blastinduced vibration's.

Mining companies perform five to ten blasting per week. Hence, daily blasting activities can be felt by people living in proximity to the areas where explosives are used. They can be uncomfortable with the blast-induced vibrations, even if the vibration levels are within the levels permissible for the structure according to the regulations. In these circumstances, the problem turns from a structural damage problem into people's complaints and lawsuits about these complaints.
When reviewing the literature, it is seen that there are a lot of studies about environmental effects of blast-induced vibrations especially for structure damage levels but few studies focus on the human perception of blast-induced vibration. Many studies have shown that the human body is sensitive to blast vibrations. The sensitivity of human body is more than 10 times greater than that of buildings [3, 4]. Even though the blast-induced vibrations problems are well known, there is a need to further investigate the human perception of blast-induced vibrations. To determine the response of people who perceive blast-induced vibrations, firstly, previous literature related to the determination of human perception to vibration have been reviewed and some of the results are presented in this section below.

People react differently to vibrations. Vibrations that cause some people annoyance do not bother others. At the same time, there is a clear and systematic relationship between the percentage of people experiencing different effects and the vibration velocity. This relationship can be determined by a statistical analysis of people's responses and can be illustrated as an exposure-effect relationship [5].

Yao et al. [6] have defined preliminary recommended control standards in their paper. They conducted a comparative analysis of the indexes and standards for the evaluation of the comfort level of blast-induced vibration. The blast-induced vibration acceleration was used to calculate comfort assessment indexes (vibration dose value (VDV), maximum weighted vibration severity (KBFmax) and annoyance rate). They found that these indexes could reflect the impact of blasting vibration on comfort to some degree. According to the authors, the VDV and $\mathrm{KBF}_{\max }$ could be used for qualitative assessment and the annoyance rate index could be used for 
quantitative assessment.

The remaining energy of blasting is transmitted outwardly and can cause damage to surrounding surface structures $[7,8]$. Structures may not show any damage at a peak particle velocity (PPV) which is between 10 ad $50 \mathrm{~mm} / \mathrm{s}$, but, people may be uncomfortable at $2 \mathrm{~mm} / \mathrm{s}$ [8].

Raina et al. [9] remarked the human response to blastinduced vibration can be physiological and/or psychological. Due to the lack of studies on the physiological effects of blasting, they investigated the impact of blast-induced vibration on the human brain. They made an experimental study with six participants (one of them was female) for the four different ground vibration values $(0.37,11.7,33.5$ and $48.25 \mathrm{~mm} / \mathrm{s}$ ). EEG (Electroencephalogram) was used in this study to investigate the function of the brain. They found that there was no major response of the brain to transitory vibrations.

The feeling of vibration and the psychological disturbance vary from person to person. Objects may move due to vibration within the structure (shaking of lamps, movement of trinkets, sounds of other household goods caused by vibration). These movements can cause different reactions by people. Considering these issues, Raina et al. [10] suggested in their study that the values suggested by Hendron and Oriard [11] could be taken as basis. According to this, the value of 0.8 $\mathrm{mm} / \mathrm{s}$ can be perceptible and the value of $5 \mathrm{~mm} / \mathrm{s}$ is found to be disturbing.

The threshold of human perception for blast vibration ground motion is around $0.762 \mathrm{~mm} / \mathrm{s}$. Depending on the activity, sensitivity, and whether or not the subject knows when the event is occurring, human subjective tolerance to vibration levels is variable, however, levels of $12.7 \mathrm{~mm} / \mathrm{s}$ annoy some people. Although complaints can occur at any level perceptible to humans, they are unusual below $2.03 \mathrm{~mm}$ per second or so [12].

To determine people's reaction to blast-induced vibration, survey studies were conducted by Lusk [5] in different neighborhoods close to quarry mines. He obtained five survey pools. The data collected by surveys were analyzed using descriptive statistics. He compared the survey pools to each other using their average values. According to the results of that study, people with technical backgrounds tend to be more comfortable than other groups. He emphasized that positive relationships with neighbors are important in terms of quarry operations.

Human response to blasting has been presented in the Blasting for Abandoned Mine Land Reclamation Final Report. Medearis [13] reported that the human body perceives vibration well but the human perception was unrelated to vibrational levels associated with structural damage. This fact had also been indicated by prior United States Bureau of Mines (USBM) work. The results of this work are superimposed on the peak particle velocity versus scaled distance plot. People find blasting perceptible at about 2.54 $\mathrm{mm} / \mathrm{s}$ and, the particle velocity of $12.7 \mathrm{~mm} / \mathrm{s}$ is unpleasant for people. These values are general since many social, economic and psychological factors affect the manner in which individual will perceive blast vibration [14].

The US Army Corps of Engineers [15] manual about drilling and blasting included human perception in the analysis. According to this manual, vibration levels that are safe for residential structures are annoying and often uncomfortable when experienced by people. Complaints from the public are as troublesome as legitimate damage claims. It is recommended that where possible, vibration levels be kept below $5.08 \mathrm{~mm} / \mathrm{s}$ to minimize the number of nuisance complaints from owners of residential structures.

Bakhtar et al. [16] evaluated results of investigation reported by Reiher and Meister [17] on the influence of the intensity of vibrations on the degree of human annoyance. According to his evaluation, the perceptiveness of vibrations is reduced when the exposure time decreases and he reported that $5.08 \mathrm{~mm} / \mathrm{s}$ was the vibration annoyance limit.

For this study, in order to investigate the effect of blastinduced vibration on a human being, vibrations were measured as a peak particle velocity in a quarry and survey study was chosen as a method of determination of human perception of blast-induced vibration. Vibration measurements are made to examine the effects of vibrations occurring during blasting on nearby structures and/or human. In vibration measurements, acceleration, frequency and particle velocities in 3 directions (transverse, longitudinal and vertical) the resultant particle velocity and the peak particle velocity are recorded. Even if the propagation speed of transverse vibration, vertical vibration and longitudinal vibration are different, peak particle velocity values (PPV) are commonly used in evaluations for structures and people in the mining sector, when current regulations and literature studies are analyzed. Considering this situation, due to the widespread use of the PPV in the mining industry, in the evaluation made within the scope of this paper, the existence of the relationship between the PPV and the survey data was investigated. Before blasting operations, volunteer participants with an age ranging between 20 and 30 years were taken to the place at a distance between 95-322 $\mathrm{m}$ from blast areas. These volunteers were surveyed about the vibrations exposure and perception, while blastinduced vibrations were recorded. 91 surveys were obtained. The results of these surveys were evaluated by statistical analysis to determine a relationship between gender and vibration perception. After that, discomfort threshold values for women and men were determined using scaled distancepeak particle velocity graphs, because the blast-induced vibrations, as measured by the peak particle velocity, are related to a scaled distance factor.

\section{RESEARCH METHOD AND FIELD WORK}

\subsection{Working areas details}

Investigations were carried out in a limestone quarry belonging to Western Anatolia Cement Plant (Bat1 Anadolu Cement Plant) located in Izmir, Turkey. That quarry is in close to populated towns. The study area is located in the east part of the Bay of Izmir. The nearest neighborhood of Bornova/Kavaklidere lies approximately 500 meters away from the south side of the quarry. Figure 1 shows the location of these areas and neighborhood close to these areas. The details of the field study are given in this section.

The geology of the environment in which the vibration propagates was investigated. Blast-induced vibrations were measured considering the variables in the geological structure. The Bornova Melange unit overlies the basement rocks in the Izmir region. The Bornova Melange was subjected to intensive tectonic deformations during and after sedimentation. Neogene age sedimentary rocks, consisting of gravelstone, sandstone, mudstone, clayey limestone and limestone, unconformably overlie the Bornova Melange. The Bornova 
Melange rocks are extremely folded and fractured. The Upper Cretaceous-Paleocene age Bornova Melange rocks exposed in the Izmir Metropolitan mainly consists of conglomerate, micritic limestone, Bornova Flysch and limestone olistoliths. Bornova Melange rocks were formed in flysch facies [18-20]. In the quarry site where the blasting occurred, limestone olistoliths of the Bornova Melange are exposed. The oldest one is dolomitic limestone. The contact between rudist bearing Cretaceous limestone and the dolomitic limestone is diachronic. The Miocene age sedimentary rocks overlie all geological units with unconformity. Volcanic rocks unconformably overlie Miocene sedimentary rock around the study area.

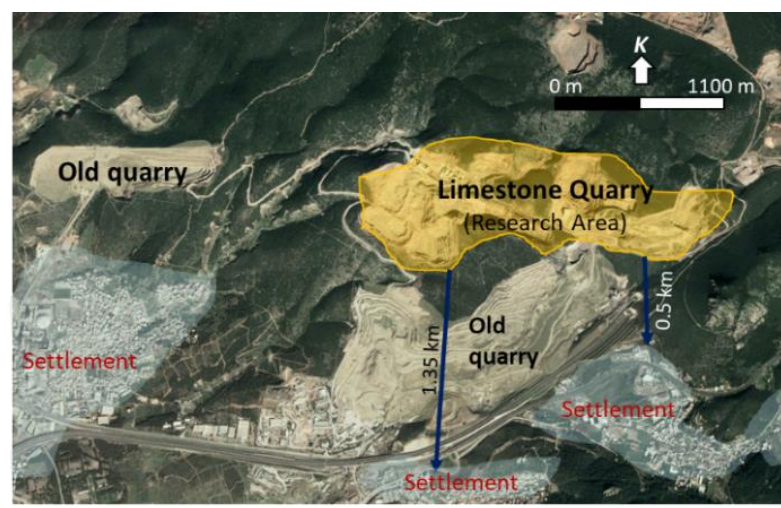

Figure 1. Location of limestone quarry

Drilling and blasting operations were followed in this quarry. 24 blast induced vibration measurements from 18 blasts were taken from different distances using a vibration measurement device. The distances from blasting sources to the nearest measurement point of the geophone are $95.5 \mathrm{~m}$ and maximum distance is $322.2 \mathrm{~m}$. The peak particle velocities are between 0.80 and $17.40 \mathrm{~mm} / \mathrm{s}$. Measurement points were somewhere on the rock mass, between the blast areas and settlements. For each blasting-operations, the maximum charge per delay has been noted. Table 1 shows the amount of explosives per delay, peak particle velocity (PPV), distances from the blast zone for all 18 blasts. Location of these blasts and measurement points are shown in Figure 2.

In these blasting operations, drill hole diameter was $89 \mathrm{~mm}$ and bench heights were between $9 \mathrm{~m}$ and $12 \mathrm{~m}$. The holes were drilled as a staggered pattern. Spacing, the distance between two holes, was between 2.5 and $3.5 \mathrm{~m}$, the burden was $2-3 \mathrm{~m}$. 25 milliseconds was the timing sequence between the holes.

\subsection{Survey studies}

A survey was developed in order to determine the perception of blast-induced vibration and the effect of gender on perceived vibration. This survey was conducted at a geophone measurement points on a rock mass. 91 surveys were obtained from the blast events.

Sampling refers to the process of selecting a part that reflects all the characteristics of the universe that forms the subject of research. The sample is a small part of the whole from which it is chosen. Studies conducted by selecting samples are economical in terms of time and cost, and can often be as valid, healthy, and reliable as the results obtained by examining the whole stage [21]. In this study, attention was paid to the sample's representation ability and its statistically sufficient size.

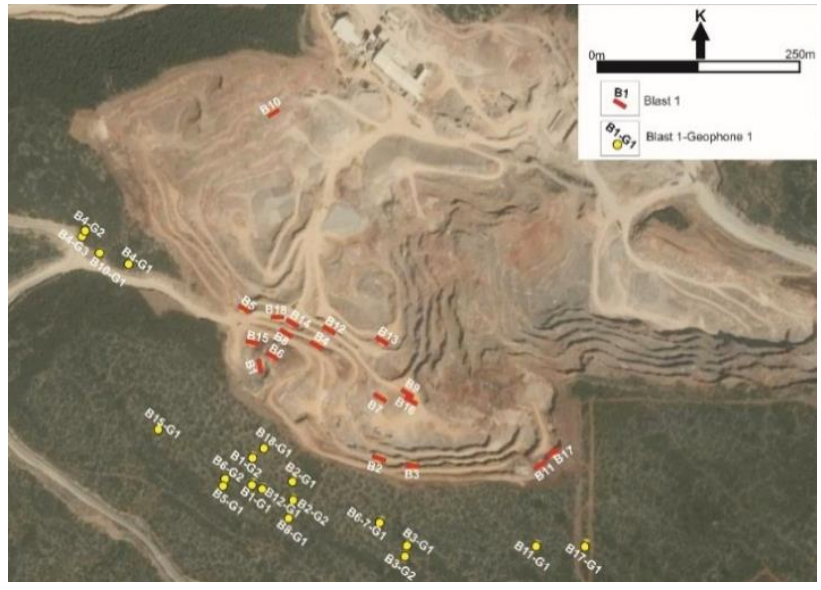

Figure 2. Location of blast areas and measurement points

The number of questions was kept limited so that the questionnaire was understandable and clear. 8 questions were created to collect data, 5 of them were about demographic characteristics, these were sex, education status, date of birth, weight, and height. Three questions were used to collect the perception of blast-induced vibration. Except for the question for measuring whether a person feels the blast-induced vibration, two questions were prepared according to 4-point Likert scale which is widely used in survey scaling technique in order to classify the vibration and determine the level of perception. These two questions should be answered on a Likert scale of 1-4 in this survey. A high score on a question indicates a high discomfort and/or high level of vibration severity classification in perceived vibration value. These questions are given below [22].

-Could you classify the severity of the vibration you felt?

None (1) Low (2) Moderate (3) High (4)

-How much did this vibration annoy or disturb you?

Not at all (1) Slightly (2) Moderately (3) Extremely (4)

Before using the survey in this study, pilot surveys were performed in the same quarry in 5 blasting with 23 surveys. Reliability analysis of this pilot surveys for the two questions with Likert type scale was carried out to determine whether the items in this survey were related to each other and the scale was reliable. Cronbach's alpha was chosen for reliability and it was calculated using SPSS software by selecting the $95 \%$ confidence interval. Cronbach's Alpha coefficient was found $78.5 \%$ which indicates a high level of internal consistency for a scale of this study in terms of two questions that are defined as items. Researchers suggest that a commonly accepted limit value for Cronbach's Alpha coefficient should be 0.7 . This means that the values for these statistics should be equal or higher than 0.7 in order that the survey are reliable [23, 24, 5]. In light of this information, when Cronbach's Alpha of pilot surveys was evaluated, it is seen that the survey is reliable.

After it was concluded that the survey was reliable, human response to vibration could be investigated using this survey. Volunteer participants were chosen with an age ranging between 20 and 30 years. $41.76 \%$ of the total number of participants is women. For two questions related to perception and comfort level, the results of the survey were analyzed using independent T-test by SPSS software. The answers were evaluated to make the comparison between groups by taking the averages of two questions. Sig (2-tailed) value called pvalue in the literature which is a part of the t-test results is important to understand the relationship between perception and gender. The alpha level was used as 5\%(0.05) in this study. 
If the p-value is smaller than the chosen alpha level, there is a meaningful relationship between the perception of blastinduced vibration and gender. The $\mathrm{p}$ value obtained from the test were 0.011 . This means that the $p$ value is less than 0.05 alpha levels. In other words, the gender differences influence the perception of blast-induced vibration according to test results. If the other output of the t-test is checked, it will be obtained that the mean of women is not equal to mean of men (Table 1). When the mean values of the group statistic are examined, it is seen that the mean values of the women are higher. While women mean is 2.1167 , men mean values is 1.6795. That is to say, women participants have a higher perception level on blast-induced vibration than men. The results of the statistical analysis presented thus far demonstrate that women participants are more heavily influenced by the blast-induced vibration than men $[22,25]$.

\subsection{Analysis of vibration data}

After the results of the survey have been investigated, women participants appear to be more sensitive to the blastinduced vibration. In this situation, evaluation of peak particle velocities should be evaluated according to gender in terms of perception and comfort level.

At the outset we recognised that we could not determine blast-induced vibrations using electrodynamic equations owing to variations in blast patterns and differences in the geological characteristics among the explosion sites. Reliable results can be generated by characterizing the measured vibrations and using empirical analyses [26]. The most used empirical formula (USBM formula) used for determining peak particle velocities of blast-induced vibration is given in Eq. (1).

$$
P P V=K\left(\frac{R}{\sqrt{W}}\right)^{-\beta}[27]
$$

PPV: Peak particle velocity $(\mathrm{mm} / \mathrm{s})$;

R: Range (m);

W: Maximum Amount of Explosive (kg) per delay;

$\mathrm{K}, \beta$ : Site Constants.

As can be seen in Eq. (1), researchers have considered distance from blast area and the amount of explosive per delay for estimation of blast induced vibration. Two-dimensional regression analysis is required to predict the peak particle velocity using amount of explosive per delay and distance. Also, Geological properties of the rock mass affect the propagation of ground vibration and they play an active role in value of peak particle velocity. These properties are evaluated as site constants. Generally, site constants $\mathrm{k}$ and $\mathrm{b}$ are determined by blast experiments. In the absence of field blast data, empirical models are used to evaluate these constants [28].

Table 1. Independent t-test analysis results of the study area from SPSS

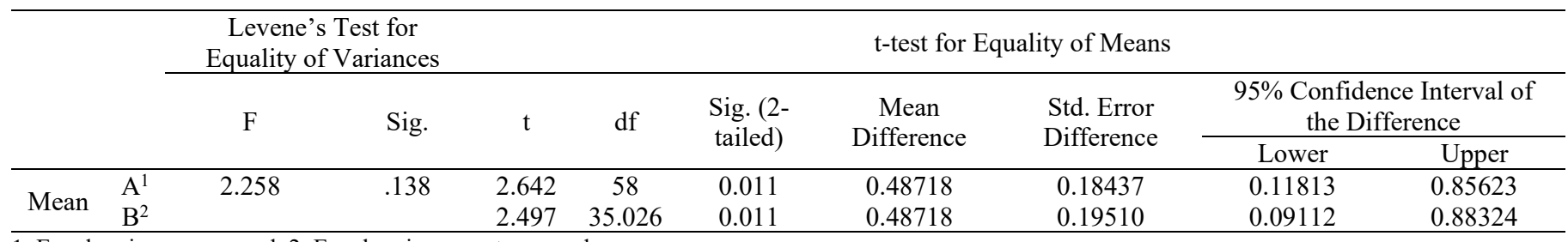

1: Equal variances assumed; 2: Equal variances not assumed

Table 2. PPV, amount of explosives, distances and scaled distances for each blast events

\begin{tabular}{|c|c|c|c|c|c|}
\hline $\begin{array}{c}\text { Blast } \\
\text { No }\end{array}$ & $\begin{array}{l}\text { Geophone } \\
\text { No }\end{array}$ & $\begin{array}{l}\text { Distance } \\
\quad(\mathbf{m})\end{array}$ & $\begin{array}{c}\text { Amount of Explosives per Delay } \\
(\mathrm{kg})\end{array}$ & $\begin{array}{l}\text { Scaled Distance } \\
\quad\left(\mathrm{m} / \mathrm{kg}^{0.5}\right)\end{array}$ & $\begin{array}{l}\text { Peak Particle Velocity (PPV) } \\
(\mathrm{mm} / \mathrm{s})\end{array}$ \\
\hline \multirow{2}{*}{1} & G1 & 140.2 & 50 & 19.8 & 10.40 \\
\hline & G2 & 108.0 & 50 & 15.3 & 8.18 \\
\hline \multirow{2}{*}{2} & G1 & 108.4 & 50 & 15.3 & 12.10 \\
\hline & $\mathrm{G} 2$ & 116.5 & 50 & 16.5 & 12.60 \\
\hline \multirow{3}{*}{3} & G1 & 109.7 & 50 & 15.5 & 8.99 \\
\hline & $\mathrm{G} 2$ & 95.5 & 50 & 13.5 & 16.70 \\
\hline & G1 & 253.6 & 55 & 34.2 & 2.69 \\
\hline \multirow[t]{2}{*}{4} & $\mathrm{G} 2$ & 322.1 & 55 & 43.4 & 2.08 \\
\hline & G3 & 320.6 & 55 & 43.2 & 2.05 \\
\hline 5 & G1 & 210.6 & 9 & 70.2 & 0.84 \\
\hline \multirow{2}{*}{6} & G1 & 240.7 & 50 & 34.0 & 2.27 \\
\hline & G2 & 161.0 & 50 & 22.8 & 4.21 \\
\hline 7 & G1 & 148.9 & 55 & 20.1 & 5.05 \\
\hline 8 & G1 & 222.5 & 29 & 41.5 & 1.79 \\
\hline 9 & G1 & 207.9 & 50 & 29.4 & 0.80 \\
\hline 10 & G1 & 273.11 & 40 & 43.2 & 2.89 \\
\hline 11 & G1 & 97.7 & 25 & 19.5 & 17.40 \\
\hline 12 & G1 & 211.3 & 50 & 29.9 & 2.21 \\
\hline 13 & G1 & 232.3 & 23 & 48.4 & 1.15 \\
\hline 14 & G1 & 210.6 & 105 & 20.6 & 3.90 \\
\hline 15 & G1 & 156.1 & 86 & 16.8 & 5.09 \\
\hline 16 & G1 & 274.1 & 55 & 37.0 & 4.68 \\
\hline 17 & G1 & 116.3 & 70.5 & 13.9 & 16.90 \\
\hline 18 & G1 & 161.6 & 50 & 22.9 & 4.35 \\
\hline
\end{tabular}


It is common to determine the peak particle velocity to evaluate the potential effect of blasting on structures. Most of regulations or criteria prefer to demonstrate the correlation between peak particle velocity and damage of structure. Most of these criteria are used to prevent structural damage due to blasting. However, it is often the human response that is the limiting factor. Vibration levels that can be felt and perceived as objectionable are usually much less than those required to cause damage to buildings. Therefore, it is often necessary to design for vibration levels that will minimize human response [14].

To make a proper blast design, the blast-induced vibrations as defined by the peak particle velocity are related to a scaled distance factor [27-31]. Having obtained the peak particle velocity and calculated the scaled distance logarithmic graphs of particle velocity versus scaled distance can be prepared. Such charts invariably show considerable data scatter so regression techniques were usually employed to determine the best fit line representing the data [14]. This technique can be also used to determine the proper amount of explosives per delay according to human perception level.

The limit of the perception of blast-induced vibration can be determined by survey results according to gender. For this purpose, measured peak particle velocities and survey data were analyzed depending on perception level using peak particle velocity-scaled distance graphs according to gender. First of all, the square root scaled distances were calculated using distance and amount of explosives per delay by Eq. (2). They are given in Table 2 .

$$
S D=\frac{R}{\sqrt{W}}[27]
$$

SD: Scaled distance factor

R: Distance (m);

$\mathrm{W}$ : Amount of explosives per delay $(\mathrm{kg})$.

The relationship between the answers to "How much did this vibration annoy or disturb you?" and peak particle velocities have been investigated together with minimum perception level. When the survey results are looked into, it can be seen that the lower perception limit which is the same value for women and men is $0.80 \mathrm{~mm} / \mathrm{s}$. On the other hand, discomfort levels change according to gender. Figure 3 (A) shows a plot of peak particle velocity versus the scaled distance with discomfort level according to women participant's answers. Figure 3 (B) is a plot of discomfort level related to scaled distance based on men participant's answers.

The evaluation made according to Figure 3 , is given in Table 3. If the distance from blast source and amounts of explosive per delay are accurately known, using scaled distance, the maximum peak particle velocity can be found from graphs given as Figure 3, so the human response can be estimated. For example, when the scaled distance is calculated as $70 \mathrm{~m} / \mathrm{kg}^{0.5}$ based on a charge per delay and the distance, the occurred peak particle velocity is $1 \mathrm{~mm} / \mathrm{s}$. That means this peak particle velocity value is not discomfortable value in terms of people regardless of gender. According to these graphs given Figure 3, human response to peak particle velocity could be estimated using the best-fit line with $\mathrm{R}^{2} 0.7$.

In this study, the effect of the geological structure on the vibration propagation was not investigated, and the on-site survey responses were associated with the data obtained as a result of the actual PPV measurements. In other words, since this study was carried out with on-site measurement results, an evaluation was made independent of the field conditions.

The results obtained are usable for limestone quarries. Because when the literature is examined, it is seen that the $\mathrm{K}$ and $\beta$ constants are close to each other in different limestone quarries. It cannot be used to evaluate the reaction of people to blasts in different geological structures.
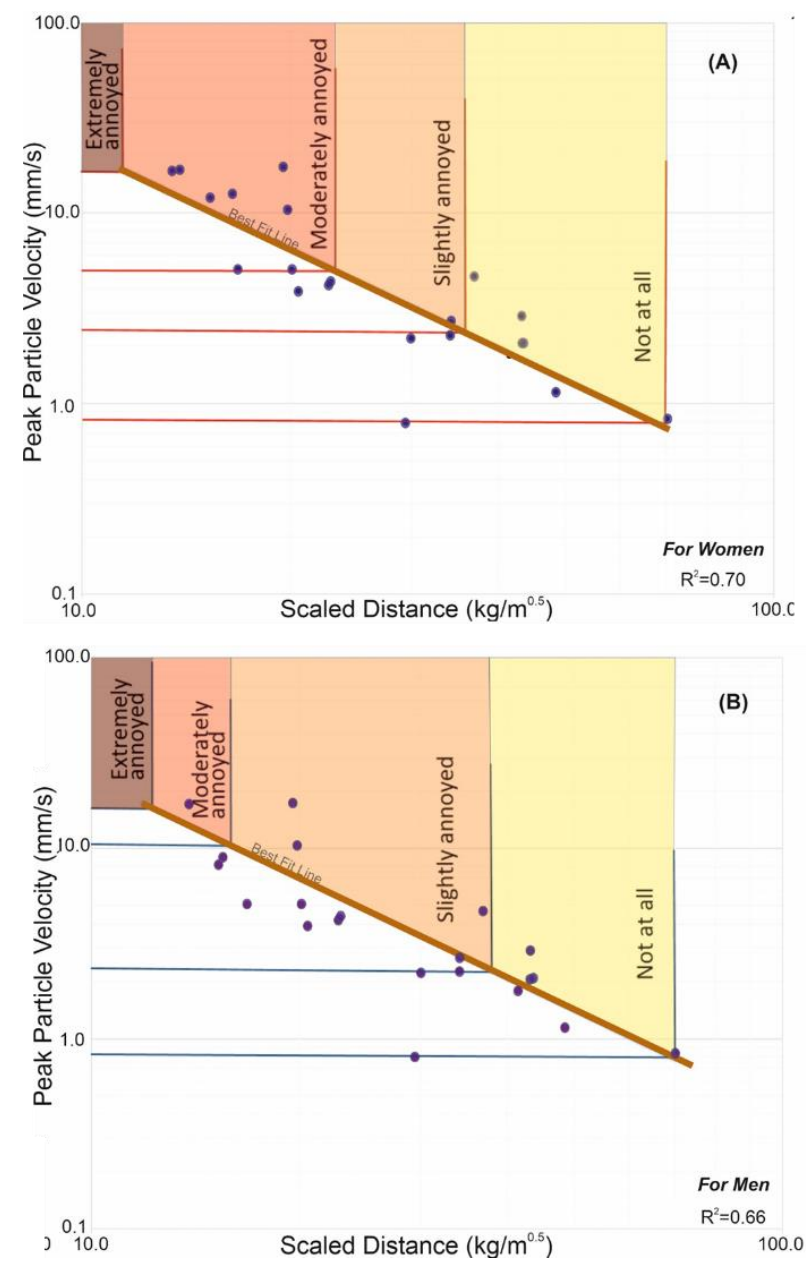

Figure 3. Peak particle velocity - scaled distance graph with discomfort level according to survey data (A) for women and (B) for men

Table 3. Perception and annoyance level evaluation in terms of gender

\begin{tabular}{ccc}
\hline $\begin{array}{c}\text { PPV }(\mathbf{m m} / \mathbf{s}) \\
\text { for Women }\end{array}$ & $\begin{array}{c}\text { PPV }(\mathbf{m m} / \mathbf{s}) \\
\text { for Men }\end{array}$ & $\begin{array}{c}\text { Limit Level } \\
\text { of }\end{array}$ \\
\hline 0.80 & 0.80 & Perception \\
0.84 & 0.84 & Not Annoyed \\
2.27 & 2.27 & Slightly Annoyed \\
5.05 & 10.4 & Moderately Annoyed \\
16.7 & 17.4 & Extremely Annoyed \\
\hline
\end{tabular}

As seen in Table 3, according to 91 surveys obtained from 18 different PPV values by paying attention to the sufficient number of samples, the perception limit is the same for women and men. But the annoyance levels change according to gender especially for high PPV values. Men's moderately annoyance limit value is almost twice the women's moderately annoyance limit. While the moderately annoying level is $5.05 \mathrm{~mm} / \mathrm{s}$ for women, it is $10.4 \mathrm{~mm} / \mathrm{s}$ for men. In this study, in order to avoid bias and to measure the response, the participants were selected from people who were familiar with blasting operations and/or have educated in mining engineering. 


\section{CONCLUSION}

In this study, perception level and discomfort levels of blastinduced vibration were investigated for women and men separately in this scientific research. The obtained results of this research are summarized below:

Survey studies were made with volunteer participants in order to determine the perception and discomfort level of blast-induced vibration in a limestone quarry, while blastinduced vibrations were recorded for the blast. Peak particle velocities obtained from measurement were between 0.798 $\mathrm{mm} / \mathrm{s}$ and $17.4 \mathrm{~mm} / \mathrm{s}$. The duration of the blast-induced ground vibration is an important parameter affecting human perception. The average monitored and the recorded vibration duration of shots is 3.75 seconds. If the exposure time to the vibration increases, an increase in discomfort levels may occur. The results of the survey were analyzed using Independent Ttest by SPSS [32]. According to test results, the gender differences influence the perception of blast-induced vibration and women participants appear to be more sensitive to the blast-induced vibration.

Peak particle velocity and scaled distance graphs were plotted and survey data related to perception and discomfort level have been evaluated for men and women, separately, using these graphs. The lower perception limit which is the same for women and men is $0.836 \mathrm{~mm} / \mathrm{s}$. But discomfort levels are affected by gender. It means that different annoyance levels were obtained according to gender. As the peak particle velocity increases, annoyance levels change according to gender. For example, while the moderately annoying level is $5.05 \mathrm{~mm} / \mathrm{s}$ for women, it is $10.4 \mathrm{~mm} / \mathrm{s}$ for men.

Table 4 shows various limit values for temporary vibrations. Annoyed limit values given in the literature are between 2.5 $\mathrm{mm} / \mathrm{s}$ and $20.00 \mathrm{~mm} / \mathrm{s}$. Although the scaling is different, the limit values found in the paper are within the disturbing range given in the literature.

Briefly, within the scope of this study, it has been observed that the vibration disturbance classification values created by evaluating the data obtained from field measurements and survey studies are also compatible with the literature.

Blast-induced vibration could affect to people. People living close to mining areas in which explosives are used for excavation should not feel uncomfortable during blasting operations. In order to avoid issues with neighbors and complaints in the blasting industry, human perception of blastinduced vibration should be considered. According to the outcome of this study, it is necessary to determine the discomfort levels of blast-induced vibration according to gender. Blasting operations should be performed taking into account discomfort levels. For limestone quarries, the graphs given in Figure 3 could be a guide to determine discomfort levels.

Table 4. Various limit values given for transient vibrations

\begin{tabular}{cccc}
\hline Humans Impact & $\begin{array}{c}\text { Ground Vibration Limit }(\mathrm{mm} / \mathrm{s}) \\
{[33]}\end{array}$ & $\begin{array}{c}\text { PPV for Transient Vibrations }(\mathrm{mm} / \mathrm{s}) \\
{[34]}\end{array}$ & $\begin{array}{c}\text { PPV for Environmental Vibration }(\mathrm{mm} / \mathrm{s}) \\
{[35]}\end{array}$ \\
\hline Not felt & $0.025-0.076$ & --- & -- \\
Barely Felt & $0.076-0.254$ & $0.25-1.50$ & $0.03-0.16$ \\
Clearly Felt & $0.254-0.762$ & $1.50-2.50$ & $0.16-1.59$ \\
Strongly Felt & $0.762-2.540$ & $2.50-10.20$ & $1.59-7.96$ \\
Annoyed & $2.540-7.620$ & $10.20-25.40$ & $7.96-19.9$ \\
Very Disturbing & $7.620-25.400$ & $25.40-30.50$ & \\
\hline
\end{tabular}

\section{ACKNOWLEDGMENT}

This work is supported by TUBITAK and DEU Department of Scientific Research Projects. The authors are thankful to engineers of Baticim Bati Anadolu Cimento Sanayii A.S. for their helping during field investigations.

\section{REFERENCES}

[1] Regulation of Environmental Noise Management. (2010). (Original name: Cevresel gurultunun degerlendirilmesi ve yonetimi yonetmeligi). (2002/49/EC) Official Gazette Number: 27601, 04.06.2010, Ministry of Environment and Urban Planning, Turkey. https://www.resmigazete.gov.tr/eskiler/2015/11/201511 18-4.htm, accessed on Sep. 22, 2015.

[2] Griffin, M.J. (2012). Handbook of Human Factors and Ergonomics, Fourth Edition, Chapter 22: Vibration and motion, New Jersey: John Wiley \& Sons, Inc., pp. 616637.

[3] Zhang, Z.Y., Zhang, W.X., Wu, X.X. (2003). Modern Hydraulic Engineering Blasting. China Water Power Press, Beijing, China.

[4] Lucca, F.J. (2003). Tight construction blasting: ground vibration basics, monitoring, and prediction. Terra
Dinamica LLC, 1-21.

[5] Lusk, B.T. (2006). An analysis and policy implications of comfort levels of diverse constituents with reported units for blast vibrations and limits: closing the communication gap. Ph.D. Thesis the Faculty of the Graduate School of the University of Missouri-Rolla in Mining Engineering, US.

[6] Yao, Q., Yang, X., Li, H. (2015). Comparative analysis on the comfort assessment methods and standards of blasting vibration. Journal of Vibroengineering, 17(2): 1017-1036.

[7] Arumugam, S., Makesh, S. (1998). Control measures on noise and vibration in mines. proceedings of the workshop on basic need for creating and sustaining a clean, safe and congenial work environment. directorate general of mines safety-tamilnadu \& kerala. Mines Safety Association, Salem, pp. 7-10.

[8] Manoj, E.V., Prasannakumar, V. (2002). Environmental impact assessment and environmental management plana case study of magnesite and dunite mine, South India. Boletim Paranaense de Geociências, 50: 21-25. http://dx.doi.org/10.5380/geo.v50i0.4152

[9] Raina, A.K., Baheti, M., Haldar, A., Ramulu, M., Chakraborty, A.K., Sahu, P.B., Bandopadhayay, C. (2004). Impact of blast induced transitory vibration and air-overpressure/noise on human brain-an experimental 
study. International Journal of Environmental Health Research, 14(2): 143-149, http://dx.doi.org/10.1080/0960312042000209525

[10] Raina, A.K., Haldar, A., Chakraborty, A.K., Choudhury, PB., Ramulu, M., Bandyopadhyay, C. (2004). Human response to blast-induced vibration and air-overpressure and Indian sceranio. Bulletin of Engineering Geology and the Environment, 63(3): 209-214. http://dx.doi.org/10.1007/s10064-004-0228-7

[11] Hendron, A.J., Oriard, L.L. (1972). Specifications for Controlled Blasting in Civil Engineering Projects, Proc. RETC, 2: 1585-1609.

[12] Rosenthal, M.F., Morlock, G.L. (1987). OSMRE Blasting Guidance Manual, TGR-1, Transmittal No 315, Office of Surface Mining Reclamation and Enforcement, United States Department of the Interior.

[13] Medearis, K. (1976). The Development of Rational Damage Criteria for Low-Rise Structures Subjected to Blasting Vibrations; Keneth Medearis Associates, Final Report, National Crushed Stone Association, Washington, D.C.

[14] Workman, L.J., Thompson, J. (1991). Blasting for Abandoned Mine Land Reclamation USBM. Contract J0289004 Calder \& Workman, Inc. Final Report.

[15] U.S. Army Corps of Engineers. (1972). CECW-EG Engineer Manual, 1110-2-3800, Systematic Drilling and Blasting for Surface Excavations, Washington, D.C. https://apps.dtic.mil/dtic/tr/fulltext/u2/a403748.pdf.

[16] Bakhtar, K., Zimmerman, H., Sagal, E., Jenus, J., Begert, C.M. (1996). Human response to explosion-induced noise and vibrations. 27th Explosives Safety Seminar, Department of Defense Explosives Safety Board, Las Vegas, Nevada.

[17] Reiher, H., Meister, F.J. (1931). The effect of vibration on people (in German). Forschung auf dem Gebeite des Ingenieurwesens, 2: 381 .

[18] Erdogan, B. (1990). Stratigraphy and tectonic evolution of the Izmir-Ankara Zone between Izmir-Seferihisar. Turk. Ass. Petrol. Geol, 2: 1-20.

[19] Koca, M.Y. (1995). Slope stability assessment of the abandoned andesite quarries in and around the Izmir city centre. Ph.D. Thesis, Dokuz Eylul University.

[20] Kincal, C. (2005). Engineering geological evaluation of geological units outcrop in and around the Izmir city centre with the help of geographical information systems and remote sensing techniques. Ph. D. Thesis, Dokuz Eylul University.

[21] Gökçe, B. (1988). Toplumsal Bilimlerde Arastirma. Ankara: Savas Yayınlari.

[22] Ongen, T., Konak, G., Karakus, D. (2018). Determination of the influence of gender on the perception of blast-induced vibration. International
Journal of Innovative Research in Science, Engineering and Technology, 7(9): 1111-1117.

[23] Kitchenham, B., Pfleeger, S.L. (2003). Principles of survey research part 6: Data analysis. ACM SIGSOFT Software Engineering Notes, 28(2): 24-27. https://doi.org/10.1145/638750.638758

[24] Nunnaly, J. (1978). Psychometric Theory. New York: McGraw-Hill.

[25] Ongen, T., Konak, G. (2018). The Influence of Gender on the Perception of Blast Induced Vibration. 4th International Conference on Engineering and Natural Sciences (ICENS). (Oral Presentation with the abstract book) Kyiv Ukraine.

[26] Kuzu, C. (2011). Taşocağı İşletmeciliğinde Patlatma Kaynaklı Etkiler. Madencilik ve Yer Bilimleri Dergisi, Turkey, pp. 64-72.

[27] Duvall, W.I., Fogelson, D.E. (1962). Review of Criteria for Estimating Damage to Residences from Blasting Vibrations. U.S. Department of the Interior, Bureau of Mines.

[28] Kumar, R., Choudhury, D., Bhargava, K. (2016). Determination of blast-induced ground vibration equations for rocks using mechanical and geological properties. Journal of Rock Mechanics and Geotechnical Engineering, 8(3): 341-349. https://doi.org/10.1016/j.jrmge.2015.10.009

[29] Ambraseys, N.R., Hendron, A.J. (1968). Dynamic Behaviour of Rock Masses. Rock Mechanics in Engineering Practices. London: Wiley.

[30] Ghosh, A., Daemen, J.J.K. (1983). A simple new blast vibration predictor (based on wave propagation laws). 24th US Symposium on Rock Mechanics (USRMS). College Station, Texas.

[31] Langefors, U., Kihlstrom, B. (1978). The Modern Techniques of Rock Blasting. John Willey and Sons, New York, U.S.A., 258-291.

[32] SPSS 15.0 software for Windows

[33] Chiappetta, R.F. (2000). Vibration/airblast controls, damage criteria, record keeping and dealing with complaints. 9th Annual BME Conference on Explosives, Drilling and Blasting Technology, CSIR Conference Centre, Pretoria.

[34] Oriard, L.L., Emmert, M.W. (1980). Short-delay blasting at Anaconda's Berkeley open-pit mine. Society of Mining Engineers of American Institute of Mining, Metallurgical, and Petroleum Engineers (AIME), Las Vegas, pp. 60-80.

[35] ISO 2631-1. (1997). Mechanical vibration and shockevaluation of human exposure to whole-body vibration part 1: General requirements. International Organization for Standardization. 